\title{
The chaos of hazard or the cosmos of determinism?
}

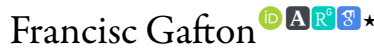 \\ Faculty of Letters, "Alexandru Ioan Cuza" University, Bd. Carol I 11, 700506 Iași, Romania
}

\section{Article info}

History:

Received July 13, 2020

Accepted August 8, 2020

Published December 27, 2020

Key words:

teleology

determinism

Neo-Darwinism

random

\begin{abstract}
All that exists emerges from the previous and is subject to some determining factors, that is, it has antecedents and causes, which have antecedents and causes, regardless of the difficulty of exhaustively analysing the elements of the causal chain (that is to quantify their forces, their hierarchy and weights, to determine their degrees of conjunction, interdetermination and collaboration, to monitor, mathematize and algorithmize their components), nothing being indeterminate and random. Such difficulty or impossibility cannot generate or constitute a reason to conclude that such complex processes would be indeterminate and random, as they are rigorously determined by a multitude of inextricably intertwined factors.
\end{abstract}

"The influence of an ideology depends upon the meaning it maintains
in the minds of its adepts, and which is spread by later commentators."

(J. Monod)

"Teleology is like a mistress to a biologist: he cannot live without her but he's unwilling to be seen with her in public."

(J.B.S. Haldane)

Preliminaries. Infinitely more complex than the human mind-which it has generated and which it contains-reality may be perceived by senses, analysed and researched upon through experiential processes of all sorts-operated on through methods and tools built for this purpose-, then thought over by thinking and rendered in linguistic ways appropriate and suiting the relationship between reality and thought.

Tending to accurately reflect reality, science obtains knowledge and organizes it systematically, based on reasoned principles, in relation to the state of reality and to the positions of that knowledge in the adjustable system of human thinking. Thus, it tries to understand the essences and to explain the phenomena researched upon and, possibly, to quantify them-both to hierarchize and predict them. And its acting force and the quality of the certainties it obtains come from its limits.

Not being the equal of reality-but merely a process, a way and an instrument generated by a tiny part thereof-, science cannot be enforced upon all entities and processes of reality, much less upon those which escape the human knowledge of reality-especially the scientific one. Neither is it absolute nor unlimited, neither can it be fulfilled by subjecting reality to the processing of thinking-which, often sifts everything through a deforming sieve made up of various human considerations. This is the scope of philosophy and theology, ethics and morality.

Having to deal only with the provable - not with the abstract, absolute and subjective entities, but with the concrete, relative and objective ones-, so as not to lose their attributes and fail into the speculative domains, the scientific research uses verified and valid methods and tools, which it applies to the objects of knowledge, looking for the causes (natural of the natural ones) and pursuing results that faithfully reflect the state of reality.

^Email address: algafton@gmail.com. 
Therefore, the scientific search does not begin with a moment before the appearance of matter (whose knowledge science seems to be able to manage), but only there does it have its start point. Therefore, to gradually come close to finding out what and how reality is, science is rather forced to seek to successively find out what an entity is not and how it does not function. Having this vital need for the negative approach - even in spite of Aristotle, of philosophers and logicians-as for a necessary and constant step on the path of understanding reality, comprehension and ordering of knowledge, the scientific process cannot go without the continuous segregation of the elements of reality, of the tireless refinement that removes the reflexive-intuitive slag and the optimal precision that adjusts concepts to the face of reality. Operated by putting to work all perspectives with the potential to provide scientific knowledge, such a path urgently requires the observance of reality and the stringing of the senses, thinking and language.

Teleology and science. At a certain moment, any scientific endeavour can get to a point where it seems to be at the beginning of all things, where material reality can no longer find its resources and principles in itself. This state makes man seek a form of pure, infinite and external energy, a primum movens, in the Aristotelian order of induction. As the establishment of the world on an immanent and transcendent principle, somehow orderly, seems to be an inevitable and inexorable necessity, beyond the equally immanent and transcendent God of the theists, the one only immanent of the pantheists and of the one only transcendent of the deists, all science of humanity is crossed by degrees and hypostases of finalism.

In the most natural way, the development and maturation of sciences brought along their secularization. The nature of the domains, of the research and of the discoveries, the empirical-inductive method and the modalities of conceptualization and of relating the man to the world-which they all developedstimulated the transition from explanations through formal and final causes to those through material and effective causes. As a consequence of this revolution, science was freed from theology and religion, and naturally began to seek in itself principles of existence and action, as well as own ways of development-a fact justified and confirmed by the fact that many explanations did not need factors outside the investigated reality. At the same time, teleology itself begins to emerge from the empire of theology (to which it did not belong essentially and naturally, just as the other classes of ancille did not belong to religioneither sciences, methods or tools), the obvious consequence being a decrease in the weight of explanations which appealed to theology and the improvement of those who stood under the teleological perspective.

On one hand, separated from religion, science has gained ground, its development bearing more and more beneficial fruits. On the other hand, the call for teleology was not completely abandoned, but rather reduced to reasonable levels. This is because teleology was not an erroneous perspective in itself, but one that, deriving from the same root as science, could have been distorted by the tendency to know and explain, and, as everything else, and as science itself, could be misused and abused. Therefore, in the $20^{\text {th }}$ century, by continuing the thinking of the great $19^{\text {th }}$ century and considering that science can only describe the world, not to explain it as if everything were pointless, along with many others, L. Wittgenstein will consider that the teleological perspective remains difficult to ignore.

Antiteleology. Not necessarily having theological and religious roots, the teleological thinking is both more complex, more nuanced and more systemic than its opponents present it, and, at the same time, less imperious than its followers present it, when both one and the others occupy exclusive positions.

Although teleology had begun learning not to correlate with theological and metaphysical speculations, and its explanatory weight had decreased in proportion to the increase in the degree of scientificity of explanations, starting with the last two decades of the nineteenth century and continuing throughout the twentieth century, one notes an excessive reaction to it. Since the life of Darwin, researchers and thinkers who passed science through seemingly materialistic ideological sieves, and who had built up a faith fed by ideals with at least two-hundred-year-old foundations, saw in the Darwinian explanation the ideal and opportune occasion to liquidate the finalist perspective-which blocked the advance of the ideological thinking they were propagating. These foundations and banners were chosen despite the fact that Darwin 
himself, who based his explanation on the action of the physical, chemical and interactional factors, was perfectly aware that neither this explanation was flawless, nor could he completely replace the others-the Lamarckian one, for example, whence it came from-nor did he solve anything other than the matter of the evolution of the living matter, through the production and diversification of species. Moreover, with demiurgic wisdom, Darwin understood not only that his explanation needed additions and arguments, but also that-unmetaphorized - it could not fall below the threshold it originally referred to-the one of the living matter.

L. Agassiz had warned of this obvious and ignorant situation: "World has appeared one way or another. The great question is how life was generated, and Darwin's theory, like all other attempts to explain the origin of life, it is simply conjectural." and J. A. Shapiro: "For those scientists who take it seriously, the Darwinian evolution functioned more like a system of philosophical belief than as a hypothesis that can be submitted to scientific testing".

This was possible because those involved in the fight against teleology took over from Darwin the ideologically exploitable elements (the blind action of natural selection, a concept that Darwin had nuanced and relativized, however), simplified aspects (natural selection as unique factor, although Darwin had emphasized and explicated that natural selection is the central factor, but by no means the only one) and especially eliminated aspects-Lamarckian or non-Lamarckian—, inconsistent with their ideology and their goals (the role of the use and non-use of structures, based on which, almost every step and in its entire work, Darwin relied his strongest reasoning to substantiate and argue his explanation; the transmission of the acquired traits, in which Darwin believed so much so that he invented a theory to explain the phenomenon; ideas about overpopulation and the inter- and intraspecific competition, which constitutes the genitorial and fundamental pillar of the very idea of natural selection; the directed evolution and the belief that there are "general purposes of life"(Darwin, 1875). Their elimination and replacement with others, then the absolutization of some and the trivialization of others-all against the grain of Darwin's beliefs and warnings - can produce a coherent theory endowed with credible attributes, but the result can neither be called Darwinism, nor can its essence or Darwinian extraction be asserted, first of all because it denies precisely the Darwinism itself.

By modifying the Darwinian explanation and amplifying its impulse with unimaginable energywhich only ideologies have and that science can never produce at such an intensity-, the Neo-Darwinists (whose doctrine had as sole source, crucial basis and perpetual purpose: the antitheleology) built a machine deemed to liquidate the finalist perspective (by abandonment, elimination and annihilation). Fuelled by ideological stakes based on a dogma built $a d h o c$ and using speculative methods and tools, this machine produced and used a combination of arguments (logical, analogical, etc., but always sophistic), through which an attempt was made to construct an infallible explanation, to replace all others, to achieve selfsufficiency and to lead to fulfilling the desideratum required by Marx's phrase: "Philosophers have only to interpret the world in different ways, but it is important to change it".

By appropriating Darwin's scientific image-a positive and progressive one-together with elements of terminology (variation, adaptation, evolution, natural selection, etc.), the Neo-Darwinists made a simple and popular idea: everything appears, exists, functions, develops and evolves on the basis of a (blind) genetic lottery, under the conditions of full equality of chances and free will. At the same time, they left aside the elements of complexity, the procedural nuances and the uncertainties of any process of authentic scientific knowledge. The result was a construct with the appearances of self-sufficiency and the ability to perpetually find in itself arguments in favour of one's own consolidation and counter-arguments of defence and attack. Moreover, it was a construct refractory to any change (even adaptive-evolutionary) and reluctant even to the advances in scientific knowledge - at least up to a certain threshold quite high. In this regard, it is of utmost relevance that after it appeared by taking over and radically changing the Darwinism, The Neo-Darwinism known several pseudo-stages-Post-Neo-Darwinism, evolutionary synthesis, modern evolutionary synthesis and modified evolutionary synthesis-which are nothing but the avatars of the 
same ideology which, once manufactured, sought with programmatic tenacity to preserve itself by freezing the initial streak of thought, conceived as inert to anything else-of course, implicitly to the progress of the scientific knowledge. This last effect was assumed by the Neo-Darwinists, who showed that no price was too high for them, as long as the destruction of the finalism equivalated with the establishment of the absolute domination.

Conceptual mosaic and discursive rhetoric. The teleological streak is so deeply human that a deep remodelling of thinking - to eliminate it altogether-can generate incalculable effects, as the presence of the finalism ensures the perpetuation of several ways of thinking and solving problems, of a way of thinking that can progress by denying anything but the freedom to think in multiple ways. However, the anti-teleological offensive-carried out with utmost diligence and total dedication-aimed at the disappearance of the idea of teleology and of the entire language.

From August Weismann to beyond Ernst Mayr - taken as benchmarks and followed more or less faithfully and nuanced by many naturalists and philosophers - the science of the nineteenth and twentieth centuries was constantly obsessed with finding irrefutable anti-theleological arguments, a process that led to the attempt to abolish any kind of proliferation of any other position-from the declared adherents of the teleological conception, passing through those who observed with honesty and probity that some theological aspects cannot be challenged as their illusory nature cannot be demonstrated nor can they be replaced with contrary aspects, and concluding with the anti-theleologizing ones, who were not NeoDarwinists.

The war was fought by all means. Firstly, a vast activity of building a complex conceptual construction was undertaken to replace and to throw into caducity the teleological one-naturally lasting over millennia. For this purpose, an entire ideational and linguistic scaffolding was built, imagining and redefining entities, processes and relationships, placing as indisputable truth, unprovable or debatable assertions, often consequences of some torticular distinctions and reasoning-guided by the intended purpose. At the same time, it was worked upon dismissing any arguments of those in another position. The series of battles was fought over many types of war field, with elaborate but unscrupulous techniques, strategies and tools, generally without too much respect for the opponent. The latter was almost always ridiculed as an irremediable prisoner of some prejudices, mysticisms or wanderings, or only accused of the inability to understand and accept reasoning and evidence qualified as irrefutable and self-evident as such, by rejecting shortly and de plano both arguments and counter-arguments. In turn, the arguments and the counterarguments of the Neo-Darwinists were always axiomatized, overrated, circular and counterfactual, the preferred one being ignoratio elenchi. Practically_as in the case of the (neo) Lamarckians-by all means, there were discouraged, discredited, repudiated and punished as heretics all those who gave any sign that could be interpreted as one of non-adherence to the Neo-Darwinian and antiteleological doctrine and dogma.

The following sketch provides an image of the situation in the latter part of the twentieth century, that is from the apogee stage - the one in which the anti-teleological argumentation reached its own peaks, in all aspects.

Probably one of the most representative researchers who fought under the Neo-Darwinism and antitheleology flag was E. Mayr. Emphasizing things that no one has denied, namely that there is a free relationship between purpose and causality and that purpose is not to be mistaken for the "final" status of a process, E. Mayr tries to build and defend the position as his predecessor, A. Weismann, that is, through all the already signalled tactics, relying especially on the discursive ones, operating numerous semantic segregations and isolating concepts until the disappearance of some and the creation of others, by amalgamation. He will do differently after claiming that terms such as teleology and teleological have been applied to the most diverse phenomena, being defined and used in various ways, erroneously, confusingly.

The task of redefining sensitive concepts is a strategy practiced by the whole Weismannian lin- 
eage, the occasion being created for the segregation and regrouping of the phenomena in arbitrary classes convenient to the one who identifies and defines them in order to reconstruct reality and concepts by word, in order to create unified instrumentation, to guide the ways of conceptualizing reality in accordance with the Neo-Darwinist purposes and dogmas.

Somehow ironically-unless the implications had not been devastating for the course of the scientific knowledge-the fact shows by itself the indispensable character for man, of the teleological "noise", and helps to attest to its grounds-at least from the human mind, if not from reality.

Before segregating the concepts of 'teleology' and 'teleological', in the footsteps of Jacques Monod, E. Mayr resumes the concepts that should have provided grounds for the for anti-teleological dogma, that is 'function' and 'program'. The distinction between the two would be that function can refer to both a physiological process and to a biological role of a structure or activity (the function of the rabbit's legs is locomotor, but the biological role of this faculty may be to get rid of predators) - only the second meaning being able to acquire teleological valences. In turn, the program is defined as encrypted or previously arranged information, which controls the process, leading to the goal. The program would contain not only the sketch of the purpose, but also the instructions for using the sketch, being something material and pre-existing for the initiation of the regulated process-a set of instructions, not a description of a situation. At the same time, since the existence of the program is inferred from the manifestations of the programmed behaviours or activities, their operation allows the acquisition of information, with structural and functional changes as a consequence 1. (Monod, 1972; Mayr, 1974).

Both the distinction between function and program, and the parallel one, between natural and artificialwhich takes into consideration functional structures, on one hand self-assembled, self-reproducible and having its development principles in their own functions, and the other hand, assembled and reproduced with energy input and external planning-are constructs oriented by the purpose of the demonstration that prepares the release of certain elements from a much more complex reality than what will remain of it. This fact is observable in the following.

Continuing in the footsteps of J. Monod and paying special attention to those who invoke the supernatural forces or a vitalist principle, E. Mayr shows that some objects of the physical world are endowed with the ability to change, a process conducted in strict accordance with the laws of nature, which interact with the intrinsic properties of the object it acts upon. For instance, an object the size of Earth, caught in the gravitational force of the Sun, necessarily becomes spherical, strictly by virtue of the relationship between the laws it is subject to and its features. If the potential is used, these processes are completed, if an external obstacle interferes (such as gravity or entropy) they are stopped, but in neither case does the effect occur by virtue of a pre-existent purpose. In the footsteps of Aristotle, both J. Monod and E. Mayr make a first segregation of the 'teleological' concept and call such automatic direction as teleomatic (Monod, 1972; Mayr, 1974, 1988, 1992).

The second segregation is made by showing that entities such as creatures, whose functional structures hold a program (such as the genetic code), act by deploying a project. This program codifies and regulates the behaviour - towards a final or term effect. Such an action, reducible to physical and chemical causes, is called teleonomic (Pittendrigh, 1958).

Referring to the automatic course of evolution, on a course of perfection, while understanding that organized structures (such as the organism) involve the orientation towards an effect, the term invented by Colin Pittendrigh is a product of the attempt to distinguish and separate the 'effect' from the 'intention'. It is part of the attempts to free science from the Aristotelian teleologism and redirect the metaphorical and teleological language.

Considering the teleonomic processes, the teleomatic ones and the adaptation through natural selection as strictly material phenomena, E. Mayr takes them out of the scope of teleology. Nevertheless, unable 
not to recognize the fact that here too there are processes and activities clearly oriented towards a goal, he will argue that this does not require the involvement of the supernatural forces because the goal is already codified in the program which governs those activities. As always, natural selection-seen as an optimization process, but not a goal-oriented one, but one that happens by virtue of inertia, only the result showing whether that change contributed or not to the adaptation-is considered to be a satisfactory explanation of the organic evolution, so as to make it useless to invoke any supernatural forces. (As a matter of fact, the matter is so complex that even accepting that the processes in the inorganic world, oriented to an end, are is simply due to the action of the laws of nature, the possibility of teleology still does not disappear completely, because, as we shall see, it is not divinity the great supporter of teleology.)

Eventually, emphasizing that such processes do not work by virtue of a future purpose, not being any causal connection behind them, and holding ground on the anti-teleological and antivitalist position, E. Mayr admits that many obscure aspects still not decoded by the current science remain under discussion, being extremely difficult to him to explain teleology which still cannot be thoroughly and fully denied in an argumentative way (Mayr, 1974, 1988, 1992).

The ten commandments. Trying to provide a clearing-edifying and hardening-fixing guide to these ideas, E. Mayr summarizes his position by stating ten statements of faith by which he draws ways to follow, mandatory for current and future anti-theleologizing thinking. As biologists have great need for elements of teleology - the idea that the biological research evades the results of physics is quite common among the theorists of the science of biology, among the philosophers of science, and among biologists, although physicists themselves accept that there are degrees of nonlinearity of the laws of physics-, E. Mayr concedes that, for biologists and in biology, the heuristic value of the teleological matter makes it a powerful tool in the biological research, from the sub-molecular to the social level. That's why he accepts as legitimate the use of language considered teleological, but adds that this fact implies neither the rejection of the physical and chemical explanation, nor the non-causal explanation.

Then, he shows that partially or totally, programs are the product of natural selection, those whose orientation towards a goal is controlled by a program being teleonomic, and those that reach an end caused by the laws of nature, and not by a program, as being teleomatic. Clearly differentiating between levels of complexity characteristic of the living nature, on one hand, and to the inanimate nature, on the other, E. Mayr shows that the teleonomic behaviour (that is programmed) occurs only in organisms (and in devices built by man), after which he adds that the teleonomic explanation is strictly causal and mechanistic, so it can serve the followers of the vitalistic conceptions. This is the most skilful way of arguing and at the same time blocking, through which: a) a concept adequate to one's own ideatic construction is built; b) that concept is monopolized; c) the opponents are denied or blocked access to that instrument; d) only the position unprovable or obviously impossible to sustain with scientific arguments is released-everything to deprive others of the ability and even the opportunity to give an acceptable answer.

Eventually, E. Mayr argues that there is no justification for describing the evolutionary processes or trends as directed towards a goal (that is in a teleological way, the selection already rewarding the occurred phenomena (mutations, re-combinations, etc.) without planning for the future-at least not in a certain way. Whereas all this does not solve the anti-teleological matter, in the most Weismannian spirit-in which what does not correspond to conception, must be denied or postponed-he concludes by showing out that the matter of legitimacy of applying the teleological term to the stationary adaptive or functional systems requires more careful analyses (Mayr, 1974), inadmissible for the time being.

As one may note, the Weismannian way of thinking and proceeding makes the Neo-Darwinists operate distinctions devoid of scientific grounds, in order to recover indispensable elements, but in the scope of the concept of 'teleology', or to argue that the true characteristic of the goal-oriented behaviour is not the existence of a mechanism which improves the precision with which the goal is attained, but the existence of the mechanism that initiates, that is, causes this goal-oriented behaviour, or that natural selection is an optimization process, but it is not goal-oriented, only after it happens will it be shown if that change 
contributes to adaptation.

The whole set of definitions is an anticipatory construction, by which teleology is split, in hope of emptying it of any essence. On one hand, separations have the role of proving that the living appears as the consequence of spontaneous processes of morphological self-constitution and self-reproduction whose principles are within itself-that is in the contained program and based on which the living is structured, operates, reproduces, develops and evolves-, protected from the effects of external actions and retro-actions. On the other hand, by reducing the teleomatic processes to the status of processes subject to the action of natural laws, and the teleonomic ones to the processes subject to the physical and chemical action, it is hoped that the teleological thinking will disappear.

But beyond all that, the fact of maximum significance-characteristic of all anti-theleologizing NeoDarwinists - is that the way of reasoning and fighting the battle is profoundly teleological.

Mutation and adaptation. On this background, an important and above-board matter concerns the determined or indeterminate character of mutations and adaptations. Although they have a rather insignificant share among the events with a genetic impact and an even smaller one for the results of the selection, mutations impress both because of the negative consequences they generate as well as due to their unpredictability. Overrated by a partial opponent of Darwin, namely Hugo de Vries, mutation has been used as a preferred-often unique-explanation by the Neo-Darwinists. Claiming that mutations occur, manifest and are selected absolutely randomly and unpredictably, they absolutize genetic inheritance and indetermination. Therefore, the emergence of a correspondence relation between a mutation and its effects was considered the fruit of mere coincidence.

Thus, firmly and repeatedly showing that function depends on structure, then on the role of the modified protein, on the interactions it participates in and on the reactions it catalyses, Monod (1972) states that these facts are not connected to the mutation itself and to its close or remote causes. On these grounds, he concludes that between the events that cause or allow an error in the replication of the genetic message and its functional consequences, there is no relationship.

The fur of the polar bear. Having appeared when a branch of the brown bears remained isolated and came to life under unprecedented geo-climatic conditions, the polar bears got a fur different from their ancestors, as compatible as possible with the conditions of the environment they live in. The Neo-Darwinist reasoning which explains the appearance of this fur-which would not be due to the organisms' adaptation to the environment but to a miraculous chain of events perfectly coordinated between them and with the environment - they are carried out imagining the events according to the following sequence of pure events: a) genes (at least two) which produce melanin, undergo a mutation; b) which leads precisely to the production of hair deprived of pigment; c) this fact affects quite a few specimens; $d$ ) of both sexes. Then follow phenomena related to adaptation and selection, the only solid aspect of the Neo-Darwinian theory, taken over from the Darwinism, but absolutized: as in that environment the holding organisms know an increase of their capacity to respond to the environmental conditions, the white fur constitutes an advantage; this fact increases the chances of survival of the mutant specimens compared to the chances of the wild type; at the same time, the breeding between polar bears, at the same time as with the decrease in cross-breeding between the two types, perpetuates the mutation and its results, which increases the number of mutant specimens, compared to those of others. Therefore, the random appearance of the mutation that brought over a fur more appropriate and more adapted to the environment-compared to the specimens which did not have this mutation-increased the chances of survival and reproduction of the mutant specimens, so that gradually, due to the action of natural selection, the white-fur bears came to eliminate and replace the brown bears.

Closely examining such narrative, it becomes clear that it has no possibility of corresponding to the reality of the processes in nature. Given that the feature under discussion is polygenic, and mutations do 
not have the strength to produce big changes, it is hard or almost impossible to accept that the mutation would have affected the fur on the entire body and that it would have manifested itself by the appearance of the final form, and not just on a part which was de-coloured-at least in the first stage. But such a partial mutation would have had insignificant chances of being taken into account and retained by natural selection. Moreover, if this is the unpredictable result of pure hazard, with no connection whatsoever with necessity or with the structural and functional utility, then any possibility is just as achievable, being very likely that the mutation occur in the directions of all shades melanin participates in. Surely, many of these blind attempts would have been rejected by natural selection, but it is just as sure that selection would have tolerated some. Otherwise it would mean that the selective pressures are extremely large-which, as a rule, it is not found. This is because, before the selective pressures reached the terribly high share necessary to such a degree of elimination of the organisms emerged as a result of the lottery of mutations, at the level of organisms, the adaptative mechanisms are powerfully activated which properly respond to the requirements of the environment, life acting on its own benefit, which means preservation and continuation (survival and reproduction). This is the fact which, as far as life is concerned, is always and unmistakeably found.

From here it is understood that the acceptance of the Neo-Darwinist scenario necessarily implies the undertaking of a perfect string of opportune coincidences in their nature, measure, mode, moment and succession: chance makes a mutation to occur, which is exactly the right one for that environment, in the optimal proportion for the good relationship with it and optimally capitalized phenotypically; then chance causes the mutation to occur in enough specimens (to have a chance of survival) and in both sexes (to have chances of reproduction). And above all, natural selection, the solitary, inescapable and the overwhelming size of the force operates according to its own determined rigors, on a field of the products of mere hazard, so that the final result holds so much optimity that some may find it planned or at least successively followed through.

All this blatantly contravene the way things happen in natural reality. Then, they can be accepted as such simply and solely at the same time with the rejection of any determinism, which, although not oriented by a presumed pre-existing goal, has this property of channelling and guiding the development of the functional structures according to the relationship between their properties and the dominants of the environment, so that events may take place on the trajectories of some causal networks.

Vehemently denying the relationship between evolution and the environmental requests, the antitheleologizers believe that the selective pressures exerted by the external conditions on the organisms are not related to the "teleonomic" performance characteristic of species, which means that, by interacting with the environment, the organism "chooses" the interactions and determines the nature and the orientation of the selective pressure that it bears (Monod, 1972). Actually, things are exactly the opposite: the organism does not choose, but it responds: a) interactionally to the nature and parameters of the pressures, and b) proportionally to the complexity and the autonomy they have. The only method of influence they have derives from the compatibility of the response to the nature and features of the requests-a response with chances of adequacy proportional to the complexity and autonomy of the body. That is, the variability and adaptability do not constitute accidents but potentials used in response.

It is as if the normal existence of systems were to naturally imply that the aberations and dysfunctions arisen during their functioning were the same as their normal structural-functional states. That is, in certain areas, conditions, and moments of the functional existence of the environment, and under the concert of the systems' components-or simply under any existential condition-aberations and dysfunctions naturally (or just somehow) found their place, usefulness, and purpose. It is as if systems were anomalous in that all anomalies and dysfunctions that appeared were not just the result of the system's errors-which would not be owed to the existence of limited stability and variability-, but parts of normality, i.e., the existence and becoming of the system implied the assimilation and perpetuation of aberations and dysfunctions, 
of abnormalities. In this case, natural selection is no longer the evolving filter that promotes the viable (in all its aspects) and eliminates that which impedes the normal functioning and continued reproduction of the system, but merely a degrading dispatcher, which lays out the errors and assures their existence (evidently as part of a system decreasingly resulting from its own becoming and increasingly replaced by a genealogy of aberations and dysfunctions).

Eventually, although adaptation - as a result-is an a posteriori state, as a process, it is a way of acting towards a goal. Of course, the goal is survival and possibly the reproduction of that organism, and the concrete modalities are related to the orientation of the functional exercise of its components, in relation to the conditions of the concrete environment.

The movements of matter. Events such as particle motions and collisions seem random, but they are subject to the action of a set of factors and actions-studied and included in what are called the laws of physics - and occur accordingly, generating something predictable, called entropy (an essential part of the second principle of thermodynamics).

As the indirect evidence of the existence of atoms and molecules, the Brownian motion, for instance, refers to the seemingly random movement of the suspended particles, with the direct effect of their collision and with the indirect one of the fluctuating change of the speed and frequency of the collisions. Although the interactional events such a particle goes through, cannot be subsumed to a pattern-from where the impression of "random" - even this case of movement can be described by applying probabilistic patterns.

Ocean currents. At the scale they unfold and act, the ocean currents present quite well-defined paths, given by the conjugated action, at different degrees, of several factors having general and contextual actions and effects-conjugated and interrelated, constant and variable. But the same currents can be seen successively at more and more detailed levels, where various variations occur in consistency with those levels and become important within them. For example, the ocean current is generated, maintained and modulated by: a) the movement of the Earth (which is related to their state of force, in its turn dependent on the relationship between mass and speed, related to the fact that it approaches or moves away from the Sun) and to its gravitational state (which is not the same in any moment); b) the geography of the ocean (which changes, which at a certain level can matter, and at another level, not); c) water peculiarities (which include temperature, viscosity); d) interaction with other currents; e) the presence of some bodies in the water (islands, marine creatures, artifacts, etc.) and so on.

At different levels and with varying degrees of implication, these factors have the potential to affect the predictability of dynamics and effect, of the ocean currents, but this fact does not mean that the results are without cause or that they would be random events.

Zooplankton. In its turn, only apparently wandering-like the planets-, the zooplankton has its existence determined by the action of a multitude of complexly intertwined factors that influence one another, each of these being determined by other factors, in a chain that starts from the ocean currents and reaches the atomic level, after including the actions of those creatures, including the zooplankton itself, selfpropelled. Considering the zooplankton of the entire planetary ocean, only that of a particular ocean, or just a specimen of each one of the few types of zooplankton, it can be observed that the actions of the factors have differentiated effects, both in position and weight, and as importance. Therefore, although, for the individual, taken as an entity, it can be important what, where, when, how and how it happens with it, for the whole and for the evolution it is irrelevant what happens with the individual. Carried out by virtue of the functioning of the Planet, the production of phytoplankton ensures the existence of the zooplankton, which participates in the functioning of the upper links and ultimately of the Planet. Although unimportant in themselves, the events a krill goes through until it dies of old age or in the 
digestive system of a whale with baleens, are determined in complex causal networks, necessary in the order of the functioning of the physical and chemical laws of Nature, lacking necessity or purpose in their perspective, of the krill, of the ocean or of the predators, but participating in the necessity of the functional existence of the successive classes of the whole.

Alea iacta est. A dice toss appears to be random to the highest degree. Nevertheless, avoiding the hurried and hazardous impression, the meticulous analysis reveals that numerous factors participate in such an act. The gripping and the throwing force of the hand, then the trajectory described by it, the topology of the dice and of the hand, the relationships between them, the nature and the effects of the elements determining the degree of adhesion between the dice and the hand (from how tight it is held between the fingers, to how loose it stays in the palm, and from the presence, to the cohesive force of the various substances on the surfaces in contact), the air composition (given by the concrete proportions-from the space of the throw-between $\mathrm{N}_{2}, \mathrm{O}_{2}$, Ar, other rare gases, $\mathrm{CO}_{2}, \mathrm{H}_{2}$, etc.), the dice parameters (size, weight, character of the edges, corners, surfaces, engravings and the substances wrapping it), then the nature of the rolling surface or only of impact and landing, its reaction force, the existence, on it, but also in the air, of vapours, of suspended particles or of dust and the like are forces of influence which, at least at the beginning of an investigation, cannot be ignored. Some of these are constants, others are variables, and this in several ways. That is, theoretically, some might be valid for any dice tossing situation (the formal parameters of the dice or of the hitting-throwing surface, for example), while others show degrees and types of variability, all with possible effects of several kinds. Thus, the circumstances of the throw may change during a set of throws: a) although it is reasonable to assume that, in the same place, air has a constant composition, the modification of the conditions is not excluded (from weather to other types of "accidents"); b) the same person does not always throw with the same force and on the same trajectory-on the contrary, empirically it can be decisively proven that this never happens quite exactly, nor regularly, nor "randomly". The factors in question, therefore, act differently for each throw of dice, by the same person and in the same place, which is likely to induce determinations in terms of the outcome, even if not all factors always have effective consequences, some mattering only in certain conjunctions and interactions, others may become negligible.

Accidens (in)separabile. Things are not completely different in the case of a series of events. It is possible for a negligent and agitated individual (due to genetic and pathological causes, the lack of education, environmental, living causes) to participate in the dice game, while consuming a cake and its syrup leaks on the carpet. An exaggerated movement causes the dice to exceed the throwing surface and be projected on the carpet. The moment when the dice is about to touch the carpet coincides with the moment when, in the place of the fall there is an ant attracted to the syrup. Although between the two sequences there can be relationships (the individual's background, his state of nervousness, the fact that he eats carelessly, along with the fall of the syrup on the carpet and the coming of ants), while among others there are none (the moment when the dice falls and the one in which a certain ant is at the end of the dice trajectory), such a chain - that, in various forms and degrees of complexity, whoever lived it in its temporal linearity-is not completely devoid of determinism. Moreover, its links can become starting points for other chains of events (either in terms of dice, carpet, cake, either in terms of the individual, his family members or the ants).

Fingerprints.Since they appear from a fertilized and then divided zygote, the monozygotic twins have the same DNA sequence. Although they will have many almost identical features, their fingerprints will not be the same, but significantly different. This is because the features of the fingerprints are not exclusively determined by genetic factors, the environmental factors being involved in their formation.

Through this-like any product both genetically and epigenetically-, fingerprints show not 
only the capacity of the same genotype to generate several phenotypes, but also the significance of this capacity, as its existence indicates a way of functioning of the genetic level, as potential that activates and acts interactively with and accommodated to the concrete environment of the individual holding that genetic constellation.

Dermatoglyphs form during the fotal period (approximately between the first and the second third of the pregnancy period). The first determinant of their configuration is genetic in nature, through several genes (some dealing directly with them, others that deal with the formation of the skin, muscles, fat, bones, the blood vessels in the area, etc.) setting the parameters of the cell growth of the whole assembly (palm). The second determinant consists of the action of the environmental factors which determine the elements of detail and shade of the dermatoglyphs.

The environmental factors are mechanical in nature (the most important of which is pressure) and act in various concrete ways (the position and the movements of the fœetus in the womb, the growth rate of the fingers, pressures and characteristics of the blood flow and of the organic substances through the skin, the pressure and the movements of the amniotic fluid, the viscosity of all these fluids, the possibility of the fingers touching the placenta), thus determining particular features in terms of the height of the protrusions, the depth of the ditches, the distances between the ditches, their lengths, widths and regularity, the patterns of the curves etc. As the ditches form in a way, the continuation of the action of the determinant factors leads to the stabilization or modification of the model which is thus gradually formed.

Although they seem random in presence and action, these factors are determined in relation to what puts them in the act and determinants in relation to the effects of their actions-all rigorously exercisedeven if the impossibility of analysing them gives them the appearance of unpredictability.

For instance, the observation of the movements of the mother and of the fotus shows that they are triggered by needs and states, arrayed by anatomical and physiological factors (mother's and fotus's traits, the resources the two of them possess and procure, as well as the way they manage them), of growth, of environment, of behaviour and interaction, temperamental factors etc.- which, in turn, have their own determinants. Then the movements of the amniotic fluid - another partial determinant of the fingerprintsoccur under the determinism of the actions caused by many factors, mainly by the movements of the mother and of the fœtus-in relation to the physical characteristics of the womb, of the placenta, of the fotus, with the amount and viscosity of the amniotic fluid, etc. (Mulvihill \& Smith, 1969; Penrose \& Ohara, 1973; Okajima, 1975; Kimura \& Kitagawa, 1986; Okajima \& Yoshida, 1986; Babler, 1991; Kimura, 1991; Bentil \& Murray, 1993; Kücken \& Newell, 2004, 2005; Cummins, 2005; Raser \& O’Shea, 2005; Kücken, 2007; Patwari \& Lee, 2008; Wertheim, 2011).

Beyond word games. Although imperfect and unable to reflect the reality, to the extent that it captures the multiple relationships thinking has (with reality, with society, with itself, with language), the language instrument can provide information not only on the language skills, but also on what is going on in thought. That is why it might be useful to observe the terms used in the antitheleologizing speech and the concepts they are trying to carry.

Although nothing is without causes and nothing happens by hazard-even if many may be foreign to man-there are several terms which try to convey a contrary conception.

Etymologically, terms such as random and hazard are equivalent because they refer to the course and the unpredictable outcome of tossing the dice. Of course, before tossing the dice, during the rolling or flying, or even a moment before freezing, nobody can know what its upper side will be. Based on calculations specific to the probability theory it is possible to make a prediction with the degree of accuracy related to that theory, applied to such an activity. Nevertheless-as it was seen-although unpredictable, the final result is not purely accidental, it being determined by the interfering, conjugated and determined action of several factors.

All this shows that the subsequent meanings for random and hazard are developed as a result of 
some summary and simplifying judgments, deprived of the grounds given by the nuanced and complex understanding of the processes of reality. The meaning thus attempted to is 'purely accidental', 'absolutely accidental', 'lacking any determinism'. This fact, however, already shows that the desire to find a term or a phrase which expresses a content of thought perfectly antinomic to that expressed by the determined term, involves a difficulty that easily turns into impossibility. Things are like this for the simple reason that thinking can invent such construct, without getting the correspondent or at least an adjacent support from reality, finding it difficult to transform - by word - the nebula into clarified form.

Random - the term often used in the Anglo-American literature and taken over internationally-can function as a pure convention, although it refers to 'at speed', 'on the run', 'hasty', 'in disarray', which is far too little compared to 'devoid of any kind and measure of determinism'.

A term such as gratuity cannot be allowed an understanding such as 'chemical independence' between function and the nature of the chemical signals that control it' (Monod, 1972), as it refers to something owed to good human pleasure, lacking the justification of sufficient reason, getting somehow close to concepts such as 'destiny' or 'fate', one dictated by the good will of gods, the other by a fatality preceding even them, and which goes beyond them and often includes them-so incomprehensible to man that, often his mind or intuition qualifies it as ... "random".

Of course, the etymological value of a word does not forbid its various semantic developments, and the lack of a suitable term does not automatically mean the existential impossibility of the concept. On the other hand, the lack of a proper term-especially after two thousand years of conceptual exercise and especially where many researchers strive with maximum inclination to demonstrate that things are as they show, and not otherwise-, seriously warns of the unclear and even forced nature of the concept. In its turn this character indicates at least the impossibility of proving the existence of a correspondent in reality, therefore, the concept could be only an embodiment, an element of a complex mental construct, equally nebulous and obscure.

In its turn, determined may refer to either the fact that the state or development of something was defined, the parameters being known, either to the fact that the existence, the functional exercise, the development and the evolution of something - thing or process - are subject to the causal determinism, that is, they are as consequence of the action of one or more direct or indirect causal factors, possibly interwoven in one or several networks. Something random, risky, free or even arbitrary can be subject to chance, to accident, and can be unforeseeable, unpredictable, but all this does not necessarily mean that it would be devoid of any determination. No matter how unpredictable for the human being, hazard does not exclude natural determinism, unfolding within the limits that determine it and that can be subjected to the calculation of probability, in various degrees. Either that something is emergent, either it is seen from the quantum perspective, it remains subject to determinism, so that absolutely anything in the known Universe is determined. In fact, the determined character-in any of its meanings-does not depend on the capacity or the possibility of the human mind to comprehend the causal relations of the network (which it can often do with the rather simple chains), to quantify order, weights and hierarchies of the factors involved in the event and to predict the event or its parameters.

As a result of the frequent and intense exercise of the skeletal muscles, in these tissues there occur changes in the DNA methylation, first in the regions that enhance transcription, associated with relevant changes in the gene expression. Although a causal relationship cannot be clearly determined, it would be hazardous to consider that human understanding and its instruments have reached their peak, so that if such a relationship has not been deciphered yet, to consider that its existence would be impossible (Lindholm et al., 2014).

Probably that here the key word is unpredictable. Of course, something is as such from the point of view of the human computer which is the brain, valid-in principle-for all humans. 
As always in the history of human science, various advances in method and tool begin to provide the theory with more and more verifiable data, and the amplification and deepening of the ability to quantify and predict complex events leads to increasingly reasonable results. Thus, more and more processes, such as mutations, are extracted from the helplessness zone, randomly (Orr, 2010; Neher \& Shraiman, 2011; Avelar et al., 2013; Kosheleva \& Desai, 2013) called, or evidence appears, that, for instance, at the level of the various non-coding and non-repetitive regions of the human genome, even the mutation rates vary on deterministic principles, and not "randomly" (Smith et al., 2002).

Given that nothing exists outside determination and that some realities cannot be predicted with accuracy (in their appearance, development and evolution), but they are subject to the laws of probability, the term which optimally renders the conjunction that generates this complex of attributes is stochastic. Depending on the level at which it takes place, such a reality is differentiated as a type of action and as a force, so that stochasticity is manifested in one way at the subnuclear level, in another at the molecular level, in another at the cellular level, at the level of the organ, organism, population, solar system, etc.

Stemming from the fact that the limits of variability-in a given place, time, system, etc.-are exceedingly large, stochasticity expresses a condition in which the possibility of a phenomenon's appearance is very high, while the predictability of the ways and conditions (when, how, where, how much, in what cases, etc.) under which it may manifest is extremely low. Therefore, the term stochastic refers to a process or product through the statistical perspective of the predictability of its conditions, not of the possibility of its appearance. It was impossible for life forms not to appear in the Universe, but the place, means, moment, duration, conditions, and other limits of their emergence were rather unpredictable.

Omnia sine Deo. The obstinacy of the supporters of the Neo-Darwinist and anti-teleologizing position, indicates, on one hand, the fear of God's presence. A fear greater than the one contained in the faith to the religious practitioner and than the one crammed in the prejudice of the superstitious one-maybe altogether. A fear which, per se, shows faith in God. One that evasive mystic-childish manœuvresfrom eluding the name and its metaphorical use, to denying the being and changing its attributes-could make him disappear, at least from this mental Universe. A God who suffered from the only fate that he could have expected from man: either by himself, either forced by human imagination, he created the foundations and the principles of existence, of development and evolution (as a demiurge), revealed himself (as a creator who ennobles creation), was taken part without consent (as a forcedly attached guarantor) to physical and mental atrocities, then burdened with all sins (as a mystic scapegoat), then judged, condemned and killed (as an impostor and a thief, or as a Father who could not be replaced after it was honoured, but only after it was dishonoured). All this happened and is thus resumed because the capacity of men, to ignore and despise, to disregard and contort is simply immeasurable-otherwise God would not have been cast out of the mundane realm, exiled to heaven, in the subconscious or elsewhere, demonized, denied like a ghost, declared dead and then metaphorized.

So, it is not God that people fear.

Nibil ad hominem pertinet. Although the divine presence and order in things and processes can be terrifying for people, given their resilience, they do not terrify them. What terrifies men is their own ability to commit the unimaginable, on behalf of something imaginable-that is, people's struggle is with other people.

From the perspective of this very discussion, all human cultures admit that there are things and processes that escape or transcend the human mind, and all admit that the divine reason transcends human reason. In some cultures, however, the divine reason is inconsistent with human reason, being incomprehensible, unpredictable and independent of it, while in others, human reason can be connected to the divine one and able to understand that - of course, to the extent and on the portions allowed to the being 
human.

In the first conception, divinity—deistically and almost atheistically separated from humanity-acts in ways and with unintelligible meanings for man, who has no other option but to act in in accordance with the way he built his own morals. Whereas the morality he built cannot be but different from the way of being of the divinity, man can only hope that, by chance and by luck, the thoughts and actions may somehow be pleasing to the divinity or at least tolerable to benefit from its discretionary mercy-even free, even unjustified.

In the second conception, the divinity behaves theistically, being involved in the world, quite clearly tracing the paths and often guiding the human being. Man can err as a result of ignorance, of misunderstanding, of erroneous execution, etc., but above all he has the opportunity to choose in knowledge of the situation proportional to the quality and degree of the religious and moral education held-which are to array the very will of the human being.

In the first conception, the imagining of an imperceptible and incomprehensible divinity is conjugated with the assumption by man of the status of legislator of his own deeds, which allows the hazard and the divine gratuitousness and leads to paroxysm, along with the random and the free human will-even of a man fumbling around to reach divinity. This fact breaks any real relationship between man and divinity, but fatally that man remains a creature which, even when it defies divinity, does so in the form of the rebellious subject.

In the second one, the imagining of an omnipresent divinity, in conjunction with the assumption of the moral and religious code drawn by the divinity, eliminates chance and establishes the norm, limits free will and highlights determination, which leads to the integration of the human life in the plan of the divinity.

Romantic persecution. After about five generations in which a minority characterized by an intransigent exclusivism attempted the absolute repudiation of the teleological conception and of the related language and a majority terrified of words entrusted with accusatory force did but behave mimetically and eventually give in, just a handful of researchers, with the great help of reality, managed to reject the situation imposed by human calculations, but denied by the way in which it exists and becomes the natural reality. After Romanticism - which, romantically, considered itself the only one which deserved to have a sense of sight and blinded everything from necessity to phonetic laws-showed its nefarious character and after its effects began to disappear, science has recovered, revealing intact its millennial fibres, in which not even the divinity is mistaken with determinism and with necessity, neither the determinism nor the necessity are anthropocentrically thought.

For over a century, the anti-deterministic and anti-teleological science has channelled all its energies to annihilate a supposed enemy-whom, every time, under certain conditions and measures finds qualitatively upright. In the meantime, it understood that -if it were possible-the elimination of even the teleological language would involve (serious) losses, which would affect the meanings of words and the messages of the statements, both with all sorts of conceptual consequences (Beckner, 1969).

All this shows that, regardless of whether the deterministic-finalist conceptual perspective springs from the natural way of the human being to understand the world, to relate to it and to reflect it in thought and through language, or it is just an acquisition along the way, once interwoven in the human being, any attempt of suppressing this perspective can generate irreparable damage that, in fact, have the capacity to annihilate or radically modify the human being.

Determinism and finalism. Once somehow appeared, matter is structured on the basis of its features and properties, it constitutes entities that operate in the environment according to the established structure and with its interactive capabilities, it develops itself-by combination and complexity-in accordance with the structural valences and with the functional and interactional capacities, adapts itself and evolves in relation to the environment, all based on the fundamentals of principle. The range of structural and 
functional and interactional potential entity it is endowed with, generates a bunch of possibilities, updatable as a result of the exercise of the entity-spent in accordance with its structural, functional and interactional features. As existence, it is not the bunch of possibilities that matters, but only what is updated-a fact occurred on determined basis (Brooks, 1895; Koonin, 2009). In this context, each step on the way, the valences and capacities may appear (structural, functional, developmental, adaptive and evolutionary), fit and willing to interact, which can induce changes in state and process, more or less quantifiable, so that determinism can know degrees that give the appearance of indeterminacy. This game happens at every step, so that, depending on the situation, some determinations will predictably prevail and others will remain unpredictable, enabling evolution to take place as a consequence of the action of the contextual forces.

Of course, it is on par with the human mind either to mystically imagine a surreal having in itself the necessary complexity to create everything that exists, either to reject the hypothesis of such pre-existence and imagine the existence of something simple and able to initiate a generating process, step by step, of a more complex reality than the human mind and which, as it gets more complex, acquires new possibilities and new degrees of autonomy, accompanied by free will and indeterminacy.

The above shows that everything that al that exists stems from something previous and it is subject to some determinant factors, has antecedents and causes, which have antecedents and causes, regardless of the difficulty of exhaustively analysing the elements of the causal chain (that is of quantifying their forces, hierarchy and weights, of establishing their degrees of conjunction, interdetermination and collaboration, of monitoring, mathematizing and algorithmizing their components), nothing being undetermined and random. Such a difficulty or impossibility cannot generate or constitute a reason to conclude that such complex processes would be indeterminate and random, as they are rigorously determined by a multitude of inextricably intertwined factors.

Darwin himself, subject to the necessities that accompany the process of scientific knowledge and which burdens the scientific demonstration, finds himself at every step forced to seek and emphasize the causes of the states and processes that he exposes and describes. Every time, he manifests a chosen and delicate consciousness of the fact that often causes are imperceptible, complex, inextricable, unknown and possibly unknowable-which does not mean that they do not exist or do not function generating their effects. Therefore, with his caution, he often shows the way he sees and conceives the relationship between cause and hazard, random, chance, as reflected in the following sequence, which opens the chapter on the very laws of variation: "So far I have talked about variations (...) as if they were due to hazard. No doubt this expression is completely incorrect, but it fully reveals our ignorance about the cause of each and every variation" (Darwin, 1957).

Even if many may be difficult to grasp by the human calculations or anticipations, all this shows that, in a causally chained reality, nothing that is physical escapes physical determinism. Graded by circumstantialization and contextualization, determinism is the only one that accompanies in array any entity and any process; nothing listens to something non-existent, such as the "random", and nor can it exist without depending on something.

In his turn, God has no explanatory value and does not deal with details either, but from its "uselessness" it does not emerge that it would not exist. And as the existence or non-existence of divinity cannot be determined and established by scientific demonstration, provided that there is no immutability, both the given and the incident are only apparent and relative. Eventually, everything seems to be subject to an unknown complex of hierarchical orders, as it was glimpsed and enunciated from the very beginning of the twentieth century: "In our aversion to the old teleology, so effectively exiled from science by Darwin, 
Francisc Gafton

we should not forget that the world, the inorganic one no less than the organic one, it is full of order. Indeed, what is the whole development of an organism if not a strict and wonderful ordering? Starting from the primordial germ, each stage and the entire sequence of stages are they not strictly orthogenetic? If variations are deviations in the directions of the processes of development, what wonder happens if in certain directions there is less resistance to variation than in others? What wonder is it if the body is so balanced as to allow both monovalent as well as polyvalent variations? (...) If a designer sets the limits of variation to reach a given end, the direction of events is teleological, but if the organization and the laws of development exclude some directions of variation in favour of others, there is certainly nothing supernatural in that, nothing that could be incompatible with natural selection. Natural selection can occur at any stage of the orthogenetic variation, can retain and then change in different directions the results over which there may have not had any prior control" (Whitman, 1906).

Although, probably, terms such as purpose or finality were conceived from the anthropocentric perspective, to express attributes of the human being's actions, subsequently extrapolated to the apparent behaviours of other entities - even non-living-a judgment emptied of the anthropological perspective (in which, as a rule, the purpose can determine the initiation and the course), could be useful to it. Following the action in determined frames of some determinant factors become determinants, the always adjustable conjunction between the cause and the path necessarily leads to a finality. As Darwin noticed when he spoke of "purposes of life" at the level of the living matter, finality is the efficient permanence (that is between optimal limits in terms of resource consumption and the effects thus produced, in relation to the existential conditions-from the body's capabilities to those of the environment). And the enduring of the living is so imperiously ordered in the weave of the living that the organisms that have errors which severely disturb and undermine the normal living can even destruct themselves.

[Translated by Adina Chirilă]

\section{Bibliography}

Avelar, A. T., Perfeito, L., Gordo, I. \& Ferreira, M. G. (2013). Genome architecture is a selectable trait that can be maintained by antagonistic pleiotropy, in "Nature Communications", 4, 2235, Crossref.

Babler, W.J. (1991). Embryologic Development of Epidermal Ridges and Their Configurations, in "Birth defects original article series", 27 (2), p. 95-112.

Beckner, M. (1969). Function and teleology, in "Journal of the History of Biology", 2, p. 151-164, Crossref.

Bentil, D.E. \& Murray, J.D. (1993). On the mechanical theory for biological pattern formation, in "Physica D: Nonlinear Phenomena", 63 (1-2), p. 161-190, Crossref.

Brooks, W.K. (1895). An Inherent Error in the View of Galton and Weismann on Variation, in "Science", 1 (5), p. 121-126, Crossref.

Cummins, H.G. (2005). Epidermal-ridge configurations in developmental defects, with particular reference to the ontogenetic factors which condition ridge direction, in "American Journal of Anatomy", 38 (1), p. 89-151, Crossref.

Darwin, Ch. (1875). The Descent of Man, and Selection in Relation to Sex, New York.

Darwin, Ch. (1957). Originea speciilor prin selecție naturală sau păstrarea raselor favorizate în lupta pentru existență, (transl. Fuhn, I.E), București.

Kimura, S. \& Kitagawa, T. (1986). Embryological development of human palmar, plantar, and digital flexion creases, in "The Anatomical Records", 216 (2), p. 191-197, Crossref.

Kimura, S. (1991). Embryologic development of flexion creases, in "Birth defects original article series", 27 (2), p. 113-129.

Koonin, E. V. (2009). Darwinian evolution in the light of genomics, in "Nucleic Acids Research", 37 (4), p. 1011-1034, Crossref.

Kosheleva, K. \& Desai, M. M. (2013). The Dynamics of Genetic Draft in Rapidly Adapting Populations, in “Genetics”, 195 (3), p. 1007-1025, Crossref.

Kücken, M. \& Newell, A.C. (2004). A model for fingerprint formation, in "EPL. A letters journal exploring the frontiers of physics", 68 (1), p. 141-146.

Kücken, M. \& Newell, A.C. (2005). Fingerprint formation, in “Journal of Theoretical Biology”, 235 (1), p. 71-83, Crossref.

Kücken M. (2007). Models for fingerprint pattern formation, in “Forensic Science International”, 171 (2-3), p. 85-96, Crossref. 
Lindholm, M.E., Marabita, Fr., Gomez-Cabrero, D., Rundqvist, H., Ekström, T.J., Tegnér, J. \& Sundberg, C.J. (2014). An integrative analysis reveals coordinated reprogramming of the epigenome and the transcriptome in human skeletal muscle after training, in "Epigenetics", 9 (12), p. 1557-1569, Crossref.

Mayr, E. (1974). Teleological and Teleonomic: A New Analysis, in Cohen, R.S. \& Wartofsky, M. W. (eds), Boston Studies in the Philosophy of Science, vol. XIV, p. 91-117.

Mayr, E. (1988). Toward a New Philosophy of Biology. Observations of an Evolutionist, Harvard, 1988.

Mayr, E. (1992). The Idea of Teleology, in "Journal of History of Ideas", 53 (1), Jan.-Mar., p. 117-135, Crossref.

Monod, J. (1972). Chance and necessity: An essay on the natural philosophy of modern biology, (transl. Wainhouse, A.), New York.

Mulvihill, J.J. \& Smith, D. W. (1969). The genesis of dermatoglyphics, in “The Journal of Pediatrics”, 75 (4), p. 579-589, Crossref.

Neher, R.A. \& Shraiman, B. I. (2011). Genetic Draft and Quasi-Neutrality in Large Facultatively Sexual Populations, in "Genetics", 188 (4), p. 975-996, Crossref.

Okajima, M. (1975). Development of Dermal Ridges in the Fetus, in "Journal of Medical Genetics", 12 (3), p. 243-250, Crossref.

Okajima, M. \& Yoshida, T.H. (1986). Ingeritance of Dermatoglyphyc Configuration in the Rat, in "The Journal of Heredity", 77 (3), p. 169-174, Crossref.

Orr, H.A. (2010). The population genetics of beneficial mutations, in "Philosophical Transactions of the Royal Society of London. Serties B: Biological sciences”, 365 (1544), p. 1195-1201, Crossref.

Patwari, P. \& Lee, R. T. (2008). Mechanical Control of Tissue Morphogenesis, in “Circulation Research”, 103 (3), p. 234-243, Crossref.

Penrose, L. S. \& Ohara, P. T. (1973). The Development of Epidermal Ridges, in “Journal of Medical Genetics”, 10 (3), p. 201-208, Crossref.

Pittendrigh, C. (1958). Adaptation, Natural Selection and Behavior, in Roe, A. \& Simpson, G. G. (eds), Behavior and Evolution, p. 390-415.

Raser, J.M. \& O’Shea, E.K. (2005). Noise in Gene Expression: Origins, Consequences, and Control, in “Science”, 309 (5743), p. 2010-2013, Crossref.

Smith, N.G.C., Webster, M.T. \& Ellegren, H. (2002). Deterministic Mutation Rate Variation in the Human Genome, in "Genome Research", 12 (9), p. 1350-1356, Crossref.

Wertheim, K. (2011). Embriology, Physiology, and Morphology of Friction Ridge Skin, in Fingerprint Sourcebook, cap. 3, p. 1-26.

Whitman, C. O. (1906). The problem of the Origin of Species, in "Proceedings of Congress of Arts and Science", 5, p. 46. 